\title{
Preparation and in-vitro / in-vivo Characterization of Transdermal Amphiphilogel Loaded with Biodegradable Polymeric Submicron Carriers of Meloxicam for Treatment of Inflammation
}

\author{
Dilesh Jagdish Singhavi ${ }^{1, *}$, Pramod Yeole ${ }^{2}$, Shagufta Khan ${ }^{1}$ \\ ${ }^{1}$ Institute of Pharmaceutical Education and Research, Borgaon (Meghe), Wardha, Maharashtra, INDIA. \\ ${ }^{2}$ Dr. Babasaheb Ambedkar Marathwada University, Aurangabad, Maharashtra, INDIA.
}

\begin{abstract}
Aim: The main purpose for this study was to develop and evaluate amphiphilogels loaded with meloxicam-submicron particles considering the benefits of the transdermal route of administration of anti-inflammatory drugs (nonsteroidal). Materials and Methods: Glyceryl monostearate $(7 \%, 9 \%$ and $11 \% \mathrm{w} / \mathrm{w}$ ) and sorbiton monostearate (span $60 ; 21 \%, 23 \%$ and $25 \% \mathrm{w} / \mathrm{w}$ ) amphiphilogels containing meloxicam-submicron particles equivalent to $0.5 \% \mathrm{w} / \mathrm{w}$ drug were formulated. Then these were evaluated through rheological, in-vitro permeation, in-vitro release, pharmacokinetics, pharmacodynamics and skin irritation studies. The rodents were chosen as subjects to conduct the pharmacokinetics study of meloxicam via oral administration and transdermally as solutions and gels, respectively. Results: It was observed that the $\mathrm{C}_{\max }$ value of drug obtained from meloxicam solution and a marketable piroxicam gel formulation were radically lower than that obtained from an amphiphilogel (FM4, containing 7\% w/w glyceryl monostearate). It was also observed that when applied transdermally, the bioavailability of meloxicam from FM4 was higher $(n=3, p<0.001)$ than 2.5 times the bioavailability of meloxicam from a solution which was orally administered. The anti-inflammatory property of FM4 was comparatively much greater than the commercially available formulations in carrageenaninduced edema in rat's paw. Conclusion: It can be concluded that the amphiphilogels loaded with meloxicam-submicron particles was found to be a safe and efficient drug delivery system for enhanced transdermal delivery of meloxicam.
\end{abstract}

Key words: Transdermal, Submicron carriers, Ampiphilogel, Bioavailability, Antiinflammatory.

\section{INTRODUCTION}

For attaining local or systemic effects, a non-invasive and useful route of drug administration is facilitated by the transdermal route. ${ }^{1} \mathrm{~A}$ dosage form should be non-irritant, should be tolerable to patients and should have required permeability so that it can be administered transdermally. Over the last 10 years, the advancement of novel controlled drug delivery systems is given significant attention and this is expected to help in longer duration drug release that is more acceptable to patients.
For transdermal distribution due to numerous reasons, biodegradable nanoparticles are considered as attractive carriers as these have advantages overconventional drug-delivery products. $^{2}$ A successful delivery system is developed by the researchers; this is mainly applied topically and is made up of chitosan (CS)tripolyphosphate nanoparticles containing aciclovir. This in turn exhibited better chemical stability. ${ }^{3}$

As proposed by a specific research work, warfarin- $\beta$-cyclodextrin CS nanocarriers
Submission Date: 11-03-2021; Revision Date: 25-05-2021; Accepted Date: 10-09-2021.

DOI: 10.5530/ijper.56.1.16 Correspondence: Dr. Dilesh Jagdish Singhavi,

Assistant Professor, Institute of Pharmaceutical Education and Research (IPER), Borgaon (Meghe), Wardha-442001,

Maharashtra, INDIA.

Email - dileshsinghavi@ rediffmail.com

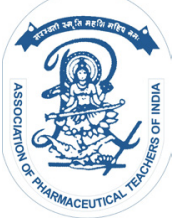

www.ijper.org 
could be developed for long-term, controlled transdermal delivery of warfarin. ${ }^{4}$ By incorporating these in an appropriate vehicle through the transdermal route, it is observed that there is a wide application of biodegradable nanoparticles. For transdermal application, researchers were successful in incorporating flurbiprofen nanostructured lipid carriers and flurbiprofen solid lipid nanocarriers into freshly formulated hydrogels. It was found that the drug delivery effect can be sustained until 24 hr. $^{5}$

A proper investigation was made for the usage of creams incorporated with hydrocortisone-loaded CS nanoparticles for percutaneous delivery. ${ }^{6}$ It was also found that the employment of CS nanoparticles was a quite capable approach for anti-inflammatory drug delivery. The use of amphiphilogels (AMPGs) in the recent years has been investigated to determine if these are convenient vehicles for the topical administration of drugs or not.

AMPGs are gels that contain a surfactant as a vehicle. ${ }^{7}$ The successful usage of AMPGs as systems for delivering cyclosporine has been described. ${ }^{8}$ Meloxicam was used as model drug in this study to avoid gastrointestinal adverse effects associates with oral administration of it. Incorportion of meloxicam (MX) was found to be effective carrier for transdermal delivery. 9

The research work was done on submicron particles (SMPs) formed from water-soluble chitosan (WSCS) and sparingly methylated $B C D$, KLEPTOSE CRYSMEß (CRYSMEB). ${ }^{10}$

The administration of amphiphilogels via transdermal route loaded with meloxicam-submicron particles (MX-SMPs) for enhancement of bioavailability has not been stated previously. Dispersion of MX-WSCS SMPs in an AMPG can additionally enhance drug delivery by increasing permeation through the skin of the payload. An AMPG can also accommodate added ingredients or excipients and thus permit the development of multicomponent formulations.

\section{MATERIALS AND METHODS}

The chitosan chlorhydrate, MX, piroxicam (PX) and KLEPTOSE CRYSMEß (CRYSMEB, 0.5 average degree of substitution) samples were donated from Mahtani Chitosan Pvt. Ltd. (Veraval, India), Dr. Reddy's Laboratories (Hyderabad, India), Zydus Cadila (Ahmedabad, Gujarat) and Roquette (Roquette Frères, Lestrem, France), respectively. From renowned places like Hi Media Lab Pvt. Ltd., (Mumbai, India) and Loba Chemie (Mumbai, India), the sorbiton monostearate (Span 60) and (GMS) glyceryl monostearate were procured, respectively. It is stated that all the others were analytical grade ingredients. Chitosan chlorhydrate $(100,000$ to $150,000 \mathrm{~g} /$ mole mean molecular weight range) was synthesized using chitosan with deacetylation of $90 \%$ and hydrochloric acid in accordance with the certificate of evaluation of it. It is also noted that with $\mathrm{N}$-acetylglucosamine (10\%) and glucosamine chlorhydrate $(90 \%)$, its linear polymer units were formulated.

\section{Experimental animals}

In-vivo experiments were done with healthy Wistar Albino rats and guinea pigs kept in institutional animal house. The animals were kept in cages and housed at a controlled temperature of $23 \pm 2{ }^{\circ} \mathrm{C}$ and a 12-h dark/ lightsequence with free access to water and food. One rat was kept in one cage. Acclimatization was done by keeping all animals for a week in the laboratory before the beginning of the experiment. Approval of animal studies was taken by the Institutional Animal Ethical committee. The experimental processes on all animals were carried out in accordance with the guidelines of the Ethical Committee.

\section{Preparation of MX-WSCS SMPs}

In our previous work, by making use of ionotropic gelation methodology, several batches of MX-WSCS SMPs were configured, ${ }^{10}$ as well as with various CRYSMEB concentrations (0, 2, 4, 12 and $20 \mathrm{mM}$ ). An excess of MX (100 mg), CRYSMEBand 0.2\% w/v WSCS was mixed in distilled water; then the final volume was adjusted upto $50 \mathrm{~mL}$. The resultant solution was incubated for $24 \mathrm{hr}$ at room temperature with magnetic stirring and then it was filtered via a cellulose membrane (pore size $0.45 \mu \mathrm{m}$ ). In the next step, the filtered solution was taken and sodium tripolyphosphate was added as cross-linking agent to it and kept for stirring at $1000 \mathrm{rpm}$ for $30 \mathrm{~min}$. By adopting the process of centrifugation at $15,000 \mathrm{rpm}$ for $45 \mathrm{~min}$, isolation of the MX-WSCS SMPs was done utilizing a cooling centrifuge (24 BL, REMI, India). ${ }^{10-13}$ As the optimum formula to incorporate in the AMPGs in the existing research work, MX-WSCS SMPs comprising $0.2 \%$ WSC, $20 \mathrm{mM}$ CRYSMEB and $0.05 \%$ sodium tripolyphosphate (TPP-mean particle size, $244.8 \pm 34.60 \mathrm{~nm}$; zeta potential, $42.21 \pm 3.11 \mathrm{mV}$; percent drug loading, $21.43 \pm 1.68 \mathrm{w} / \mathrm{w}$ ) was preferred, when we consider the previous work as foundation. ${ }^{10}$

\section{Preparation of AMPGs loaded with MX-WSCS SMPs}

In a porcelain dish, accurately weighed amounts of a solid gelator (Span 60 or GMS) were taken and then 
a fraction of Tween 80 was combined to it. Then with intermittent stirring for $10 \mathrm{~min}$, the dish was retained at a $60^{\circ} \mathrm{C}$ in water bath. The solid gelator was diffused in the liquid surfactant and the resultant was a homogeneous phase. By utilizing a homogenizer, MX-WSCS SMPs, methylparaben and butyl hydroxyl anisole were dissolved in the residual fraction of the Tween 80 and then combined to the gelator phase under high-speed stirring $(5000 \mathrm{rpm})$ as well as cooling. Then at room temperature, the formulations were kept overnight. ${ }^{7,8}$ In Table 1, all the formulations with their specific formulations are listed.

\section{Rheological study}

For examining the viscosity of every formulation, a Brookfield CAP 2000+viscometer (Brookfield Engineering Laboratories, Inc., USA) was used. On a temperature-sensitive plate at $20^{\circ} \mathrm{C} \pm 1{ }^{\circ} \mathrm{C}$, two or three drops of the samples were placed and then it was subjected to shear at diverse shear rates by utilizing Cone No. 03 for revealing the viscosity. Each measurement was elaborately studied for a span of $30 \mathrm{sec}$. As the calculation of shear stress was done, a graph of the shear rate was meticulously plotted against the shear stress.

\section{In-vitro release study}

By using a Franz cell (vertical diffusion cell-diameter, 2 cm; capacity, $20 \mathrm{~mL}$ ), in-vitro release study was conducted. The AMPGs were retained on a Dialysis Membrane-70 (pore diameter $2.4 \mathrm{~nm}$, cut off $12-14 \mathrm{kD}$, HiMedia). This Dialysis Membrane-70 had been drenched previously with isopropyl myristate to imitate a lipophilic barrier like horny layer of skin i.e. the stratum corneum. The acceptor phase was phosphate buffer $(\mathrm{pH}$ 7.4).By utilizing a thermostat; this was upheld at $37^{\circ} \mathrm{C} \pm 1^{\circ} \mathrm{C}$,

\begin{tabular}{|c|c|c|c|c|c|c|}
\hline \multirow[t]{2}{*}{ Ingredients } & \multicolumn{6}{|c|}{$\begin{array}{l}\text { Formulations containing meloxicam } \\
\text { loaded nanoparticles }\end{array}$} \\
\hline & $\sum_{i}^{\Gamma}$ & $\sum_{\amalg}^{N}$ & $\sum_{L}^{M}$ & $\sum_{L}^{J}$ & $\sum_{i=1}^{10}$ & $\sum_{4}^{\infty}$ \\
\hline Meloxicam* $(\%$ w/w) & 0.5 & 0.5 & 0.5 & 0.5 & 0.5 & 0.5 \\
\hline Span $60(\%$ w/w) & 21 & 23 & 25 & & & \\
\hline GMS (\% w/w) & & & & 7 & 9 & 11 \\
\hline $\begin{array}{l}\text { Butyl hydroxyl anisole } \\
\qquad(\% \mathrm{w} / \mathrm{w})\end{array}$ & 0.1 & 0.1 & 0.1 & 0.1 & 0.1 & 0.1 \\
\hline $\begin{array}{l}\text { Methyl paraben } \\
(\% \mathrm{w} / \mathrm{w})\end{array}$ & 0.1 & 0.1 & 0.1 & 0.1 & 0.1 & 0.1 \\
\hline Tween 80 & q.s. & q.s. & q.s. & q.s. & q.s. & q.s. \\
\hline
\end{tabular}

*Meloxicam-loaded nanoparticles equivalent to $0.5 \% \mathrm{w} / \mathrm{w}$ meloxicam of formulation $\mathrm{FM}_{4}$ were added in the above formulations. under magnetic stirring. From the acceptor $1 \mathrm{~mL}$ samples were taken at fixed intervals for $24 \mathrm{hrs}$ and then it was substituted with a fresh buffer solution. By utilizing a spectrophotometer, the MX released quantity was determined. ${ }^{14-17}$ The drug release information was subjected to zero-order model [Eq. (1)], first-order model [Eq. (2)] and Higuchi model[Eq. (3)]. To describe the release mechanism from the AMPGs, the Korsmeyer-Peppas model [Eq. (4)] was exploited. ${ }^{18-20}$

$$
\begin{aligned}
& \mathrm{Mt}=\mathrm{kt} \\
& \operatorname{lnM}=\ln \mathrm{Mo}-\mathrm{kt} \\
& \mathrm{Mt} / \mathrm{M} 8=\mathrm{kt} 1 / 2 \\
& \mathrm{Mt} / \mathrm{M} 0=\mathrm{ktn}
\end{aligned}
$$

At time zero, M0 represents the initial quantity of drug released. On the other hand, the quantity of drug released is denoted by $\mathrm{Mt}$ at time $\mathrm{t}$. It is understood that $\mathrm{k}$ is a kinetic constant that is characteristic of the drug/ polymer. Finally, a diffusion exponent characteristic of the release mechanism is represented by $n$. For the Korsmeyer-Peppas equation, the release mechanism is considered to be Fickian diffusion when the value of $\mathrm{n}$ is equal to 0.5 . On the other hand, for $n=1$, the release is zero-order. A non-Fickian or anomalous mechanism is indicated by the values of $0.5<n<1$. It is due to both polymer chain relaxation and drug diffusion.

\section{In-vitro permeation study}

Porcine back surface was obtained from a local slaughter house. The external surface was segmented by scalpel to obtain whole skin samples. Integrity of sections were visually checked and stored in frozen state. Nearly before permeation studies, the sections were warm up to room temperature. Small sections $\left(\sim 3 \mathrm{~cm}^{2}\right)$ were cut for positioning Franz diffusion cells. ${ }^{21}$

By using a Franz diffusion cell (diameter, $2 \mathrm{~cm}$; capacity, $20 \mathrm{~mL}$ ), the determination of in-vitro permeability of the AMPGs was performed. In the next step, between the acceptor and donor compartments, a porcine skin was positioned and this skin was taken from a local slaughterhouse. The phosphate buffer ( $\mathrm{pH}$ 7.4) was utilized as a receptor, whereas the formulation was utilized as the donor. The usage of aluminum foil was made to seal the donor compartment, while keeping the system at $37^{\circ} \mathrm{C} \pm 1{ }^{\circ} \mathrm{C}$ on a magnetic stirrer. From the acceptor medium, $1 \mathrm{ml}$ of samples was taken at the predetermined intervals $(0,1,2,4,8,12,18,24 \mathrm{hr})$; then these were immediately substituted with a fresh buffer solution. For conducting a thorough analysis, double- 
beam UV-visible spectrophotometer was used for the samples that get collected until $24 \mathrm{hr}$. Making use of the equation, the permeability coefficient was determined. . $^{15,22-25}$

$$
\mathrm{P}=(\mathrm{dQ} / \mathrm{dt}) / \mathrm{ACo},
$$

Where the rate of permeation is denoted by $\mathrm{dQ} / \mathrm{dt}$, A denoted the effective mucosal surface area and the initial concentration in the donor chamber is denoted by Co.

\section{Pharmacokinetic study}

The Institutional Animal Ethical Committee (IAEC) permitted the procedure for the studies. The particular rodent that was considered for bioavailability studies were Wistar Albino rats. A thorough external examination of the animals' skin was conducted to find out the abnormalities. For the experimental study, only male rats weighing between $180 \mathrm{~g}$ and $230 \mathrm{~g}$ were chosen. An area of skin of the dorsal side was clean-shaved, which was about $9 \mathrm{~cm}^{2}$. The rats were maintained under examination for a span of $24 \mathrm{hr}$ to detect any problematic consequences of the shaving, before applying FM4 and a PX transdermal formulation which is commercially available. Three groups were formed having six animals each (Table 2). The animals were made to fast overnight, but these were supplied with water ad libitum previous to the administration of MX.

Group I was orally fed MX $(1 \mathrm{mg} / \mathrm{kg})$ in phosphate buffer ( $\mathrm{pH}$ 7.4). Approximately equal doses were received by Group II and Group III $(1.25 \mathrm{mg} / \mathrm{kg}$ of MX/PX) of FM4 (AMPG containing 7\% w/w GMS and $0.5 \% \mathrm{w} / \mathrm{w} \mathrm{MX})$ and commercial PX $(0.5 \% \mathrm{w} / \mathrm{w}$ $\mathrm{PX}$ ) transdermal formulations, respectively. In order to cover the dosing area, an adhesive patch stuck to the animal's skin. For the withdrawal of blood samples, the tail vein was chosen predose at $0 \mathrm{hr}$ and then post dose at $1,2,4,6,8,12,18$ and $24 \mathrm{hr}$; mainly the serial blood sampling technique was used for this. At alternate points of time, three anesthetized rats were used. Utilization of tubes was made for the collection of samples, including

\begin{tabular}{|c|c|}
\hline \multicolumn{2}{|c|}{ Table 2: The treatment of groups in the } \\
pharmacokinetic study.
\end{tabular}

sodium heparin as an anticoagulant. To acquire the plasma, the blood samples were centrifuged and kept at $-20^{\circ} \mathrm{C}$ until analysis. ${ }^{15,26}$

\section{HPLC method of estimation of MX and PX in plasma $^{15,27}$}

\section{Chromatographic conditions}

A mixture of $50 \mathrm{mmol}$ sodium acetate solution and acetonitrile in ratio $1: 1$ ( $\mathrm{pH}$ was made to 3.3 with addition of glacial acetic acid), mobile phase; Hypersil ODS C $_{18}(5 \mu \mathrm{m}, 250 \mathrm{~cm} \times 4.6 \mathrm{~mm})$, column; $1.0 \mathrm{~mL} / \mathrm{min}$, flow rate; $20 \mu \mathrm{L}$, injection volume; $25^{\circ} \mathrm{C}$, temperature; $10 \mathrm{~min}$, run time; $355 \mathrm{~nm}$, detection wavelength; internal standards (IS), PX and MX.

\section{Formulation of solutions (Stock and working standard)}

By the usage of dimethylformamide and methanol (as a diluent) in the ratio $2: 98 \mathrm{v} / \mathrm{v}$, stock solutions $(1 \mathrm{mg} / \mathrm{mL})$ of MX and PX were made separately. Working standard solutions of concentrations $1.25,2.5,5,10,20,40$, $80,100,120,160$ and $200 \mu \mathrm{g} / \mathrm{mL}$ were made from the stock solutions. For both the drugs, the same solvent was employed.

The formulation of the standard calibration curve in plasma

Working standard solutions $(10 \mu \mathrm{L})$ of the drugs were spiked into centrifuge tubes containing the aliquots of $90 \mu \mathrm{L}$ drug-free plasma pipetted into centrifuge tubesto attain final concentrations of $0.125,0.25,0.5,1,2,4,8$, $10,12,16$ and $20 \mu \mathrm{g} / \mathrm{mL}$. An amount of $10 \mu \mathrm{L}$ of $100 \mu \mathrm{g} / \mathrm{mL}$ IS and mixture of acetonitrile and $70 \% \mathrm{v} / \mathrm{v}$ perchloric acid $(1: 1(\mathrm{v} / \mathrm{v})$ ratio] $(50 \mu \mathrm{L})$ as protein precipitating solution were mixed to the subsequent mixture for a time span of $1 \mathrm{~min}$. For duration of $10 \mathrm{~min}$, the plasma samples were centrifuged in a cooling centrifuge at $4^{\circ} \mathrm{C}$ at $10,000 \mathrm{rpm}$. A similar treatment was given to $100 \mu \mathrm{L}$ of drug-free plasma. The supernatant layer was collected following the centrifugation and it was then injected into the HPLC system. Standard

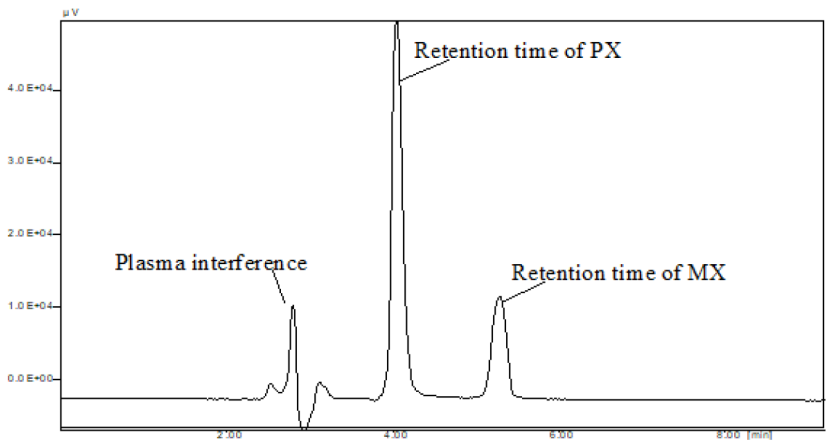

Figure 1: Chromatogram of plasma spiked with meloxicam and piroxicam. 


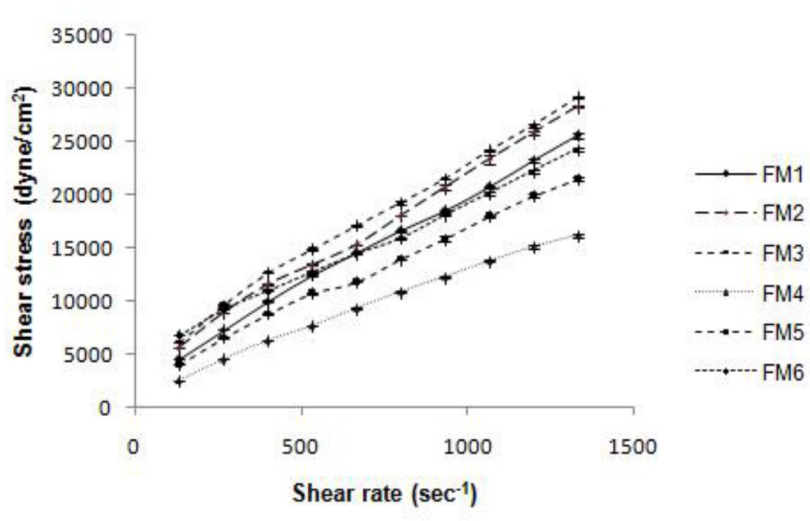

Figure 2: Rheograms of formulations FM1, FM2, FM3, FM4, FM5 and FM6.

curves, as a purpose of the theoretic concentration, were achieved from linear square regression analysis of the drug/IS optimum ratio of area. Then the intercept, slopes and correlation coefficients were carefully calculated. For preparing the standard calibration curves of PX and MX, MX and PX were taken as internal standards, respectively. At each level, the peak area ratio (drug/IS) was meticulously calculated. Finally, graphs of the concentrations of MX and PX $(\mu \mathrm{g} / \mathrm{mL})$ versus the peak area ratio were plotted. Plasma interference

\section{Preparation of sample solution}

With $10 \mu \mathrm{L}$ of IS solution $(100 \mu \mathrm{g} / \mathrm{mL}), 100 \mu$ l of plasma was combined thoroughly and then it was vortexed for $10 \mathrm{sec}$. An amount of $50 \mu \mathrm{l}$ of above mentioned protein-precipitating solution was added to this mixture. The final mixture obtained was vortexed for $2 \mathrm{~min}$ and then this was subjected to $15 \mathrm{~min}$ of centrifugation at $10,000 \mathrm{rpm}$. Around $20 \mu \mathrm{l}$ supernatant was directly injected into the HPLC instrument for investigation.

\section{Estimation of drugs in plasma}

Under the chromatographic conditions that are mentioned previously, the standard and sample solutions were injected and chromatograms were obtained. The response factors (peak area ratio of the drug to the IS) of the standard solution as well as the samples were calculated. Then to calculate the MX concentration in plasma samples, the calibration curve was employed. The blank plasma samples were studied, just preceding to the examination of MX standard composition. For the analysis of drugs, not any interference was detected within the blank plasma. The peaks were defined in a clear and utmost accurate manner. It was also observed that the retention times of PX and MX in rat plasma were $4.0 \mathrm{~min}$ and $5.2 \mathrm{~min}$, respectively (Figure 1).

\section{In-vivo anti-inflammatory study}

For studying the in-vivo performance and antiinflammatory action of the developed formulations, a carrageenan-induced rat paw edema study was conducted. The study was permitted by the IAEC. In total, there were four groups of male rats $(180-230 \mathrm{~g})$ and this included two control groups as well, with each group comprising six animals. Markings were made on the rats right hind paw just behind the tibia-tarsus junction and then $0.1 \mathrm{~mL}$ carrageenan solution $(1 \% \mathrm{w} / \mathrm{v})$ was injected. The inflamed paws were kept submerged up to the fixed mark in the plethysmograph at $0,1,2,4$, $6,8,12,18$ and $24 \mathrm{hr}$. All the while the changes in the paw volumes were carefully noted down. Then a transdermal application of the formulations (FM4 and the commercial PX formulation) was made, but exception was maintained for the rats of the control groups. To be precise, the rats in one of the control groups were injected with saline solution $(0.9 \%$ $\mathrm{w} / \mathrm{v} \mathrm{NaCl}$ ) without drug. An amount of $0.1 \mathrm{~mL}$ of carrageenan $(1 \% \mathrm{w} / \mathrm{v}$ in $0.9 \% \mathrm{NaCl}$ solution) was injected in the right hind paw (at the subplantar region) of each rat just post $30 \mathrm{~min}$ of transdermal application of preparation FM4 and the commercial PX formulation. An adhesive patch taken and was glued directly to the animal's skin to enclose and protect the dosing area. For one whole day, the first reading just after the injection and the successive volumes of paw were observed and measured properly. Then a calculation and comparison was done for the average paw edema volume of each group with those of the control groups. ${ }^{5,15,28,29}$

The percent edema inhibition was estimated by means of the following equation:

Percent edema inhibition $=(1-\mathrm{Vt} / \mathrm{Vc}) \times 100$,

where

$$
\begin{aligned}
\mathrm{Vt}= & \text { average edema volume of test group } \\
\mathrm{Vc}= & \text { average edema volume of the control } \\
& \text { group. }
\end{aligned}
$$

\section{Irritation testing on skin of guinea pigs}

IAEC approved the skin irritancy testing of the optimized formulation. The test subjects were basically 5 guinea pigs of either sex weighing 400-500 $\mathrm{g}$ and a thorough examination was done. The process began with depilating the backs of the guinea pigs and an area of $4 \mathrm{~cm}^{2}$ was marked on each side. One side served as the test side and the other as the control. The study was performed $24 \mathrm{hr}$ after the depilation. For one whole week, the formulation was applied ( $0.5 \mathrm{~g} /$ guinea pig) once a day, while cotton bandages were used to enclose the application sites. All the guinea pigs were strictly kept under observation 
for sensitivity and reactions, if there was any and then these were graded as follows: ${ }^{30-32}$

1. 'No reaction: 0 '

2. 'Slight, patchy erythema: 0.5 '

3. 'Slight but confluent or moderate but patchy erythema: 1 '

4. 'Moderate erythema: 2'

5. 'Severe erythema with or without edema: 3'

\section{Data analysis}

By utilizing one-way analysis of variance, a comparison of data in terms of mean values obtained from different tests was carried out followed by Tukey-Kramer multiple comparisons post-test when $p<0.05$. A comparison of the data in terms of mean values was conducted for the skin irritation study, using a one-way analysis of variance and this was followed by the Dunnett multiple comparison test using GraphPadInstat Software. By using the PK Solutions $2.0^{\mathrm{TM}}$ non-compartmental pharmacokinetic data analysis software package, the data were fitted; and this software is particularly used for the determination of pharmacokinetic parameters.

\section{RESULTS}

\section{Preparation of AMPGs loaded with MX-WSCS SMPs}

For preparing an AMPG system, GMS and Span 60 were used as gelators. Optimized smooth and spherical MX-WSCS SMPs with $244.8 \pm 34.60$ nmmean particle size and $42.21 \pm 3.11 \mathrm{mV}$ zeta potential were selected for incorporation into AMPG system. A simplistic method was used to prepare the surfactant gels in which MX-WSCS SMPs were incorporated: the gelator (Span 60 or GMS) and the fluid phase were combined and heated up unless the gelator dissolved/dispersed completely in the solvent phase. MX-WSC SMPs were mixed in it and the mixture was then simultaneously cooled. At lower concentrations, GMS (7\% w/v) tends to form gels when compared with Span 60 (21\% w/v). Butyl hydroxyl anisole $(0.1 \% \mathrm{w} / \mathrm{w})$ and methylparaben $(0.1 \% \mathrm{w} / \mathrm{w})$ were then mixed as an antioxidant and an antimicrobial agent, respectively.

\section{Rheological study}

It was found that the viscosity of the AMPGs had quite an impact on the rate of drug release and spreading on the skin. In an effort to understand the nature of the gels as well as to determine their action when applied on skin as drug delivery vehicles, the gel flow properties were investigated thoroughly. It is rightly observed that for predicting the effect of the formulation and improving its overall quality and stability, the rheological properties are vital. In Figure 2, the rheograms of the AMPG formulations are clearly shown in which the applied shear stress has been plotted as a function of the shear rate. The formulations showed pseudoplastic behavior, just as it can be observed in the rheograms, in which the viscosity decreases with increasing shear rate.

\section{In-vitro release study}

It was observed that the simulated transdermal conditions were used in in-vitro release test. It also played the most important part in characterizing the formulations that

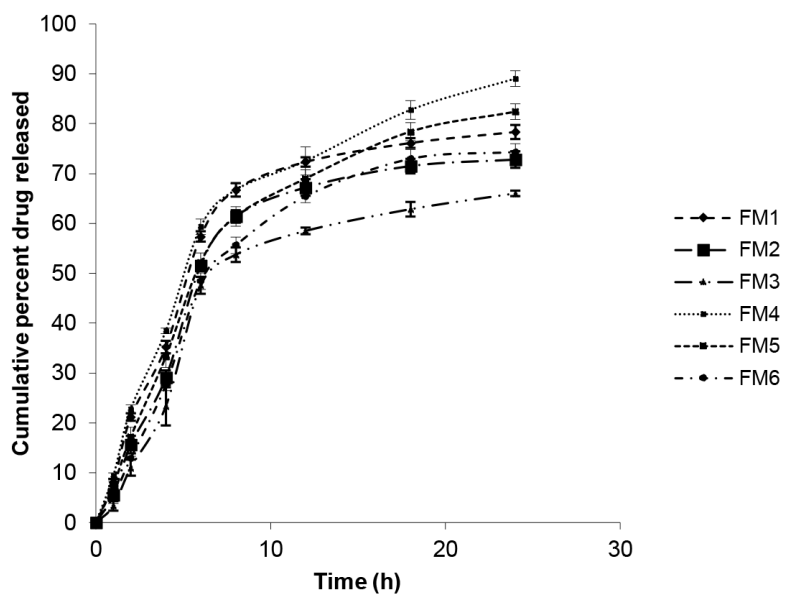

Figure 3: Comparison of cumulative amounts of meloxicam released from formulations FM1, FM2, FM3, FM4, FM5 and FM6.

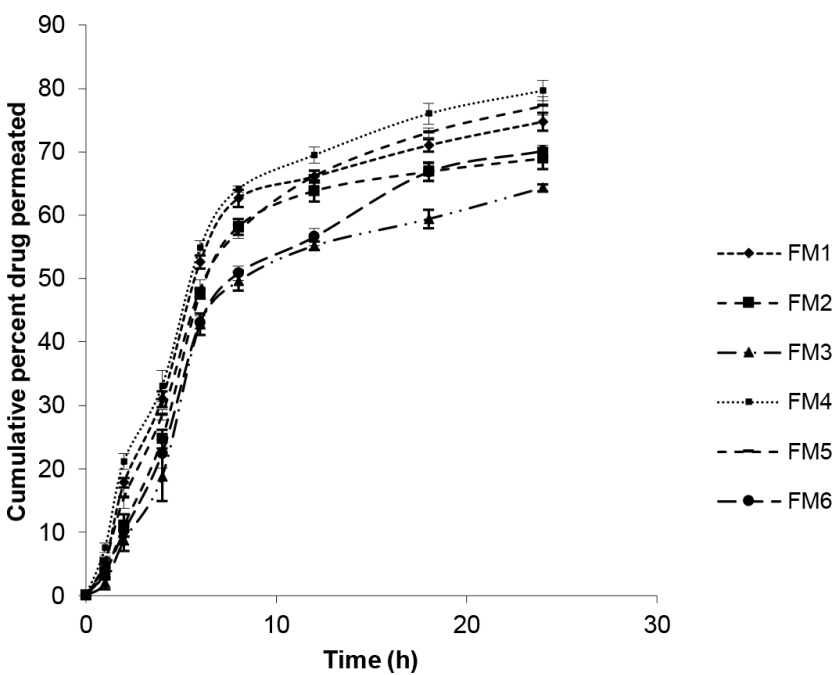

Figure 4: Comparison of cumulative amounts of meloxicam permeating from formulations FM1, FM2, FM3, FM4, FM5 and FM6. 


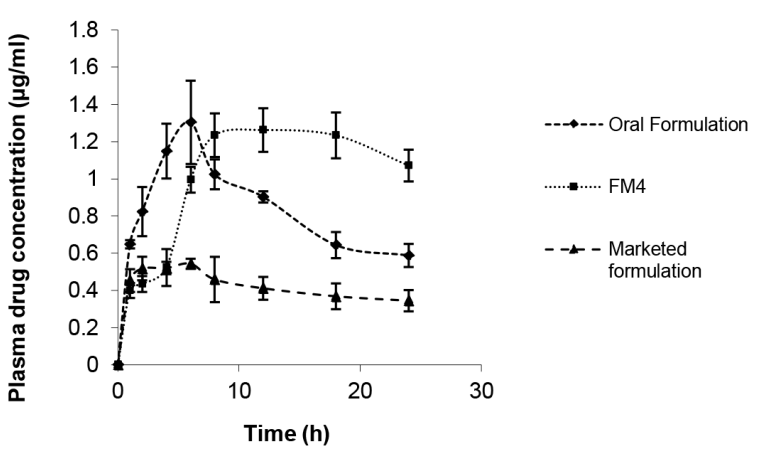

Figure 5: Plasma concentrations of drug at different time points after oral and transdermal administration of formulations.

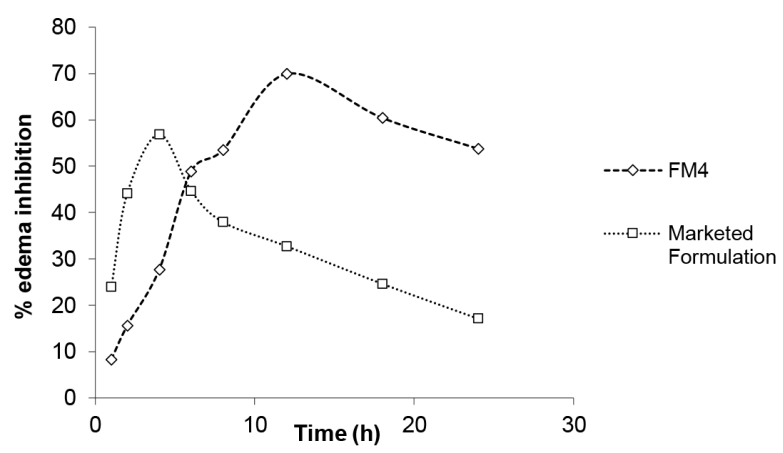

Figure 6: Percent edema inhibition after application of FM4 and commercial piroxicam formulation.

were developed. The conditions were maintained as close to in vivo conditions as possible. As shown in Figure 3, the in-vitro release profiles of the gel formulations containing MX-WSCS SMPs were studied. After exactly $24 \mathrm{hr}$, the maximum MX release $(89.05 \% \pm 1.57 \%)$ was showed by the AMPG formulation FM4. The resulting regression constant $\left(r^{2}\right)$ was accurately fitted to Higuchi kinetics. There was a gradual linear drug release from the AMPGs. The percent cumulative drug released was $66.03 \% \pm 0.55 \%$ to $89.05 \% \pm 1.57 \%$ after 24 hrs.

\section{In-vitro permeation study}

To understand the transdermal permeation behavior of the AMPGs, in-vitro skin permeation studies were conducted. An application of AMPGs containing MX-WSCS SMPs was made on porcine skin. The MX permeation with GMS/Tween 80-based gels was comparable with that of Span 60/Tween 80-based formulations (Figure 4). Increase in gelator concentration leds to significant decrease in permeation rate of drug $(n=3, p<0.01)$.

\begin{tabular}{|c|c|c|}
\hline Formulation & Parameter & Value \\
\hline $\begin{array}{l}\text { Meloxicam oral } \\
\text { solution }\end{array}$ & $\begin{array}{c}\mathrm{C}_{\max }[\mu \mathrm{g} / \mathrm{mL}] \\
\mathrm{T}_{\max }[\mathrm{hours}] \\
\mathrm{AUCC}_{0-24 \mathrm{~h}}[\mu \mathrm{g} \text { hours } / \mathrm{mL}] \\
\mathrm{T}_{1 / 2}[\text { hours }] \\
\mathrm{AUC}_{0 . \infty}[\mu \mathrm{g} \text { hours } / \mathrm{mL}]\end{array}$ & $\begin{array}{c}1.30 \pm 0.22 \\
5.00 \pm 1.10 \\
20.29 \pm 1.04 \\
19.07 \pm 0.95 \\
35.08 \pm 2.48\end{array}$ \\
\hline FM4 & $\begin{array}{c}\mathrm{C}_{\max }(\mu \mathrm{g} / \mathrm{mL}) \\
\mathrm{T}_{\max }[\text { [hours }] \\
\mathrm{AUC}_{0-24 \mathrm{~h}}[\mu \mathrm{g} \text { hours } / \mathrm{mL}] \\
\mathrm{T}_{1 / 2}[\text { hours }] \\
\mathrm{AUCC}_{0-\infty}[\mu \mathrm{g} \text { hours } / \mathrm{mL}]\end{array}$ & $\begin{array}{c}1.26 \pm 0.12 \\
11.33 \pm 1.63 \\
24.75 \pm 2.20 \\
46.73 \pm 2.04 \\
94.01 \pm 3.60\end{array}$ \\
\hline $\begin{array}{l}\text { Commercial } \\
\text { piroxicam } \\
\text { formulation }\end{array}$ & $\begin{array}{c}\mathrm{C}_{\max }[\mu \mathrm{g} / \mathrm{mL}] \\
\mathrm{T}_{\max }[\mathrm{hours}] \\
\mathrm{AUC}_{0-24 \mathrm{~h}}[\mu \mathrm{g} \text { hours } / \mathrm{mL}] \\
\mathrm{T}_{1 / 2}[\text { hours }] \\
\text { AUC }_{0-\infty}[\mu \mathrm{g} \text { hours } / \mathrm{mL}]\end{array}$ & $\begin{array}{c}0.54 \pm 0.02 \\
6.33 \pm 1.51 \\
9.82 \pm 0.67 \\
48.65 \pm 2.17 \\
31.42 \pm 1.38\end{array}$ \\
\hline
\end{tabular}

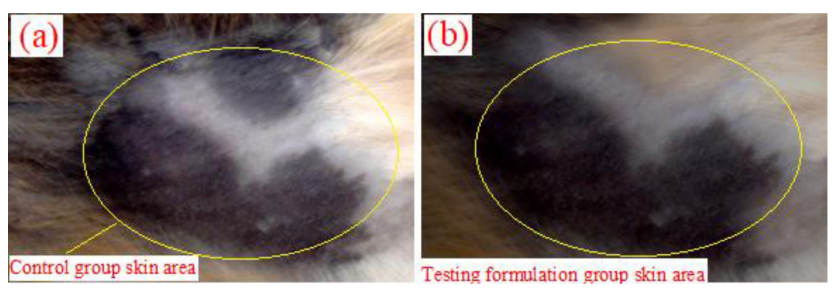

Figure 7: Photographs showing skin irritancy test of a) Control b) FM4 formulation.

\section{Pharmacokinetic study}

To compare their bioavailability values, the MX-WSC SMP-loaded transdermal gels were applied on the backs of the rats. In Figure 5, the plasma MX and PX concentration profiles versus time after application is elaborately shown. The maximum MX concentration with FM4 was reached in $11.33 \mathrm{hrs} \pm 1.63 \mathrm{hr}$. The $\mathrm{C}_{\max }$ value of FM4 was $1.26 \mu \mathrm{g} / \mathrm{mL} \pm 0.12 \mu \mathrm{g} / \mathrm{mL}$, which was higher than that of the commercial PX formulation, $0.54 \mu \mathrm{g} / \mathrm{mL} \pm 0.02 \mu \mathrm{g} / \mathrm{mL}$ significantly $(n=3$, $p<0.001)$ (Table 3).

\section{In-vivo anti-inflammatory study}

The inflammation was significantly $(n=6, p<0.01)$ reduced by the formulations understudy and the reduction was sustained. The maximum inhibition $(69.92 \%)$ was observed with formulation FM4 right at $12 \mathrm{hr}$. On the other hand, the inhibition with this formulation was more than 50\% up to $24 \mathrm{hr}$ (Figure 6).

\section{Skin irritancy in guinea pigs}

It is always observed that irritancy is an unwelcome side effect of transdermal systems. It may result from various 
reasons: (1) erratic drug penetration, ${ }^{33}$ (2) compliance (as irritation may to a certain extent influence the patient's response to drug therapy), ${ }^{31,34}$ and (3) probable sensitization. ${ }^{35}$ For their skin irritancy potential, FM4 and the commercial piroxicam formulation were tested by using guinea pigs. It was observed that both these formulations produce no skin irritation as no statistically significant $(n=5, p>0.05)$ (0.4689) difference was noticed between these formulations and the controls (Figure 7).

\section{DISCUSSION}

Leaching of MX due to hydration on interaction with the aqueous phase during storage may be led by inclusion of hydrophilic WSCS SMPs loaded with MX in a hydrogel. This might result in an initial high-burst release after dermal application. A vehicle that can prevent premature release of the drug before application is required because of this phenomenon. As the carrier allows the structure of the MX-WSCS SMPs to be retained with no leaching of MX, the use of a non-aqueous AMPG is opted for. This is the reason for incorporating MX-WSCS SMPs in an AMPG. Gel formation occurs when the sol phase is cooled in formulations prepared by utilizing GMS and Span 60 . By the cooling procedure, the gelator solubility in the solvent is basically reduced, thus resulting in a reduced affinity of the gelator toward the solvent and closed arrangement of gelator molecules; this might lead to a unified system all throughout the liquid phase, while immobilizing it completely. ${ }^{7,8}$ Compared with Span 60 $\left(52^{\circ} \mathrm{C}\right.$ to $\left.54^{\circ} \mathrm{C}\right)$, the higher melting point of GMS $\left(59^{\circ} \mathrm{C}\right.$ to $61^{\circ} \mathrm{C}$ ) could be responsiblefor its low solubility in the solvent. Hence, this may cause decrease in levels of interaction between gelator and solvent as well as gelation at low concentrations. ${ }^{7,8} \mathrm{~A}$ significant increase in the AMPG viscosity was observed when the gelator concentration was increased. In all the formulations, shear-thinning which is a required property for application of topical formulations on skin was observed. It was suggested that a high-density gelator network was formed by the rise in viscosity of AMPG with increase in gelator concentration. The fluid phase is entrapped to a greater degree by the more unified network of the gelator entraps, as a result of which the gel consistency is improved to quite an extent and the viscosity of the gel was increased as well.

At the minimum concentration required for the preparation of a gel, the viscosity of the Span 60/ Tween 80 gels was found to be higher than that of the GMS/Tween 80 gels. It might be because of higher concentration of Span 60 needed to form a gel. The remarkable benefits of formulating AMPGs loaded with MX-WSCS SMPs were shown by the in-vitro release study. It was observed that the release rate of MX decreased as the concentration of the gelator was increased gradually. A high-density vehicle film might be formed around the surface of the MX-WSCS SMPs due to the use of a higher concentration of the gelator, thus resulting in the decrease in the rate of drug migration from the particulate system to the acceptor medium. The release rate of MX from the GMS/Tween 80 gel formulations was greater than that of the Span 60/Tween 80 AMPG formulations. This might be due to the high partitioning of the drug from the GMS/Tween 80 gel. This is because when compared with the ratio of Tween 80 to Span 60, it was seen that the HLB ratio of Tween 80 to GMS was greater. ${ }^{8}$ The maximum cumulative MX permeation $(79.65 \% \pm 1.61 \%)$ at 24 hrs was that of the GMS/Tween 80-based gel formulation FM4. This is in agreement with an observation that penetration enhancer action of GMS, thus steadily increasing the topical penetration of indomethacin and urea. ${ }^{36}$ It was confirmed that MX possibly permeates through human skin by the permeation of drug of all the formulations through rat abdominal skin. The permeability coefficient were found to be $7.23 \pm 0.38 \times 10^{-5}, 6.27 \pm 0.69 \times 10^{-5}$ $5.44 \pm 0.73 \times 10^{-5} 7.76 \pm 0.89 \times 10^{-5} 6.87 \pm 0.73 \times 10^{-5}$ and $5.80 \pm 0.24 \times 10^{-5} \mathrm{~cm} /$ second for FM1, FM2, FM3, FM4, FM5 and FM6, respectively. This reflects that with increasing gelator concentration, there is a slight decrease in the drug permeation rate and, in turn, in the gel viscosity too. A reduction in the evaporation of moisture from the surface of the skin was brought about by the presence of the MX-WSCS SMPs and components in AMPGs, which results in skin hydration. Hence a decrease in the level of the skin barrier property is resulted by this increased hydration, which in turn enhances the absorption. ${ }^{37}$ This might be because of an increase in the dimensions of the aqueous pores that exist in the barrier layer of the hydrated skin, thus resulting in an increase in the connectivity of the pathway channel. ${ }^{38}$ Chitosan, ${ }^{39}$ glyceryl monostearate, ${ }^{40}$ cyclodextrin, ${ }^{41}$ and Tween $80^{42}$ have been observed to act as permeation enhancers. The barrier property of the skin can be altered by these components, resulting in increased drug permeation. Due to a reversible alteration of the integrity of the stratum corneum, surfactants with polyoxyethylene chains might enhance drug permeation through the rat skin model. ${ }^{43}$

By the oral administration of MX within $6 \mathrm{hr}$, the $\mathrm{C}_{\max }$ value was attained and a sharp drop was observed subsequently. Within 6 hrs, greater MX plasma levels 
were attained; and until the last sample with formulation FM4, these were maintained. In respect to oral administration, FM4 was observed to enhance the half-life of MX 2.45-fold. The increase in the $\mathrm{AUC}_{0-\infty}$ (area under the curvefrom time 0 extrapolated to infinite time) $(94.01 \mu \mathrm{ghr} / \mathrm{mL} \pm 3.60 \mu \mathrm{g} \mathrm{hr} / \mathrm{mL})$ of MX after the transdermal application of AMPG formulation was significantly $(n=3, p<0.001)$ high compared with the AUC $_{0-\infty}$ of orally administered MX $(35.08 \mu \mathrm{g} \mathrm{hr} / \mathrm{mL}$ $\pm 2.48 \mu \mathrm{g} \mathrm{hr} / \mathrm{mL}$ ). Hence, this distinctly indicates toward improved bioavailability of MX with the drug delivery through transdermal route. On the application of transdermal AMPGs, enhancement in plasma levels of MX was attained in the present study. By the formation of MX-WSCS SMPs containing CRYSMEB, the solubility of MX in skin layers might be increased. The fact that solubility of drug in the layers of skin was sharply increased in the presence of CRYSMEB, which is confirmed by the presence of the plasma concentration of MX for maximum period just $24 \mathrm{hr}$ after the removal of the formulation. Thus from this it can be said that the effects of the transdermal AMPGs last beyond the treatment period. The likely reason behind this may be the plasma drug concentration, which was sustained steadily for a longer period in the case of the AMPGs when compared with the commercial PX formulation. Because of the slower drug release, the anti-inflammatory effect of FM4 was sustained for an extended period. This may be because of the structure of the AMPGs and its surface-active properties. By the free drug present on the surface of the MX-WSCS SMPs, the fast onset of the action of the prepared formulation is explained; this drug basically precipitated during the configuration of the SMPs. The fact that the optimized AMPG formulation can be applied to skin without the risk of skin irritation was indicated by skin irritation studies.

\section{CONCLUSION}

Over a specific period of $24 \mathrm{hrs}, \mathrm{FM} 4$ displayed sustained drug release behavior. The performance of the AMPG formulations is majorly dependent on the type of gelator used for their preparation. The results of the permeability study indicate that the AMPGs containing MX-WSCS SMPs exhibited an optimum lipophilicity and hydrophilicity balance as the structure of skin consists of stratum corneum (lipophilic nature) and viable epidermis and dermis (hydrophilic nature). This can be explained with the help of the balancing nature of the AMPGs. It was then observed that the pharmacokinetic parameters obtained with transdermal administration of these formulations showed significant differences from those that were obtained with oral administration. The results indicated that the retention of drug in the body for a prolonged period and has an extended action due to thelonger half-life of the drug with gel formulations in rats. These formulations signify a very efficient non-irritant carrier for skin preparations for local/ systemic effects, in which enhanced drug permeation is anticipated. Thus, the treatment of inflammation in diseases such as rheumatoid arthritis, spondylitis and musculoskeletal disorders can be revolutionized by the formulation containing MX-WSCS SMPs, which is basically done by enhancing the clinical efficacy compared with existing formulations.

\section{Ethics approval and consent to participate}

Animals were indigenously bred in the institute. Study was started after getting the approval from Institutional Animal Ethical committee (Approval number: IPER/ IAEC/2010-11/12, approval date: 22-01-2011).

This article does not contain any studies with human subjects performed by any of the authors.

\section{ACKNOWLEDGEMENT}

The authors would like to thanks Dr. Reddy's Laboratories (Hyderabad, India), Mahtani Chitosan Pvt. Ltd., (Veraval, India), Zydus Cadila (Ahmedabad, Gujarat) and Roquette Frères (Lestrem, France) for the supply of gift samples of MX, chitosan chlorhydrate, piroxicam (PX) and KLEPTOSE CRYSMEß, respectively.

\section{CONFLICT OF INTEREST}

The authors declare that they don't have any conflict of interest.

\section{ABBREVIATIONS}

CS: Chitosan; AMPGs: Amphiphilogels; SMPs: Submicron particles; WSCS: Water-soluble chitosan; CRYSMEB: KLEPTOSE CRYSMEß; MX: Meloxicam; PX: Piroxicam; IAEC: The Institutional Animal Ethical Committee.

\section{REFERENCES}

1. Upadhyay G, Verma S. Recent trends in transdermal drug delivery system-a review. Adv Biol Res. 2014;8(3):131-8.

2. Badri W, Eddabra R, Fessi H, Elalssari. Biodegradable polymer based nanoparticles: dermal and transdermal drug delivery. J Colloid Sci Biotechnol. 2014;3:141-9.

3. Hasanovic A, Zehl M, Reznicek G, Valenta C. Chitosan-tripolyphosphate nanoparticles as a possible skin drug delivery system for aciclovir with 
enhanced stability. J Pharm Pharmacol. 2009;61(12):1609-16. doi: 10.1211/ jpp/61.12.0004, PMID 19958582.

4. Khalil SK, El-Feky GS, El-Banna ST, Khalil WA. Preparation and evaluation of warfarin- $\beta$-cyclodextrin loaded chitosan nanoparticles for transdermal delivery. Carbohydr Polym. 2012;90(3):1244-53. doi: 10.1016/j. carbpol.2012.06.056, PMID 22939337.

5. Bhaskar K, Anbu J, Ravichandiran V, Venkateswarlu V, Rao YM. Lipid nanoparticles for transdermal delivery of flurbiprofen: formulation, in vitro, ex vivo and in vivo studies. Lipids Health Dis. 2009;8:6. doi: 10.1186/1476511X-8-6, PMID 19243632.

6. Katas H, Hussain Z, Ling TC. Chitosan Nanoparticles as a Percutaneous Drug Delivery System for Hydrocortisone. J Nanomater. 2012;2012:1-11. doi: $10.1155 / 2012 / 372725$.

7. Jibry N, Heenan RK, Murdan S. Amphiphilogels for drug delivery: formulation and characterization. Pharm Res. 2004;21(10):1852-61. doi: 10.1023/b:ph am.0000045239.22049.70, PMID 15553232.

8. Prasad V, Kumar N, Mishra PR. Amphiphilic gels as a potential carrier for topical drug delivery. Drug Deliv. 2007;14(2):75-85. doi: 10.1080/10717540600642431, PMID 17364871.

9. Fetih $\mathrm{G}$. Meloxicam formulations for transdermal delivery: hydrogels versus organogels. J Drug Deliv Sci Technol. 2010;20(6):451-6. doi: 10.1016/S17732247(10)50078-9.

10. Singhavi DJ, Khan S, Yeole PG. Improvement of dissolution behavior of poorly water soluble drugs by biodegradable polymeric submicron carriers containing sparingly methylated $\beta$-cyclodextrin. J Mater Sci Mater Med. 2013;24(4):941-9. doi: 10.1007/s10856-013-4866-9, PMID 23392967.

11. Calvo P, Remunan-Lopez C, Vila-Jato JL, Alonso MJ. Novel hydrophilic chitosan polyethyleneoxide nanoparticles as protein carriers. J Appl Polym Sci. 1998;63:125-32.

12. Maestrelli F, Garcia-Fuentes M, Mura P, Alonso MJ. A new drug nanocarrier consisting of chitosan and hydoxypropylcyclodextrin. Eur J Pharm Biopharm. 2006;63(2):79-86. doi: 10.1016/j.ejpb.2005.12.006, PMID 16527473.

13. Janes KA, Fresneau MP, Marazuela A, Fabra A, Alonso MJ. Chitosan nanoparticles as delivery systems for doxorubicin. J Control Release. 2001;73(2-3):255-67. doi: 10.1016/s0168-3659(01)00294-2, PMID 11516503.

14. Pénzes T, Blazsó G, Aigner Z, Falkay G, Eros I. Topical absorption of piroxicam from organogels--in vitro and in vivo correlations. Int J Pharm. 2005;298(1):47-54. doi: 10.1016/j.jpharm.2005.03.013, PMID 15893893.

15. Ah YC, Choi JK, Choi YK, Ki HM, Bae JH. A novel transdermal patch incorporating meloxicam: in vitro and in vivo characterization. Int $\mathrm{J}$ Pharm. 2010;385(1-2):12-9. doi: 10.1016/j.ijpharm.2009.10.013, PMID 19833177.

16. Yener G, Dal O, Uner M. Effect of vehicles on release of meloxicam from various topical formulations. Open Drug Deliv J. 2009;3(1):19-23. doi: 10.2174/1874126600903010019.

17. Patel D, Dasgupta S, Dey S, Ramani YR, Ray S, Mazumder B. Nanostructured Lipid Carriers (NLC)-Based Gel for the Topical Delivery of Aceclofenac: Preparation, Characterization, and In Vivo Evaluation. Sci Pharm. 2012;80(3):749-64. doi: 10.3797/scipharm.1202-12, PMID 23008819.

18. Colombo P, Bettini R, Santi P, Peppas NA. Swellable matrices for controlled drug delivery: gel-layer behaviour, mechanisms and optimal performance. Pharm Sci Technol Today. 2000;3(6):198-204. doi: 10.1016/s14615347(00)00269-8, PMID 10840390.

19. Peppas NA. Release of bioactive agents from swellable polymers: theory and experiments. In: Anderson JM, Kim SW, editors Recent advances in drug delivery systems. New York: Plenum Press; 1984. p. 279-89.

20. Ozdemir N, Ordu S, Ozkan Y. Studies of floating dosage forms of furosemide: in vitro and in vivo evaluations of bilayer tablet formulations. Drug Dev Ind Pharm. 2000;26(8):857-66. doi: 10.1081/ddc-100101309, PMID 10900542.

21. Sarheed O, Rasool BK. Development of an optimised application protocol for sonophoretic transdermal delivery of a model hydrophilic drug. Open Biomed Eng J. 2011;5:14-24. doi: 10.2174/1874120701105010014, PMID 21629673.

22. Alves MP, Scarrone AL, Santos M, Pohlmann AR, Guterres SS. Human skin penetration and distribution of nimesulide from hydrophilic gels containing nanocarriers. Int J Pharm. 2007;341(1-2):215-20. doi: 10.1016/j. ijpharm.2007.03.031, PMID 17482392.

23. Miyazaki S, Takahashi A, Kubo W, Bachynsky J, Löebenberg R. Poly n-butylcyanoacrylate (PNBCA) nanocapsules as a carrier for NSAIDs: in vitro release and in vivo skin penetration. J Pharm Pharm Sci. 2003;6(2):238-45. PMID 12935436.

24. Jain D, Pathak K. Design, characterization, and evaluation of meloxicam gel prepared by suspension and solution polymerization using solubility parameter as the basis for development. AAPS PharmSciTech. 2010;11(1):133-42. doi: 10.1208/s12249-009-9369-0, PMID 20077041.

25. Mahrous GM. Proniosomes as a drug carrier for transdermal delivery of meloxicam. Bulletin of Pharmaceutical Sciences Assiut. 2010;33(2):131-40. doi: 10.21608/bfsa.2010.64728.

26. Yuan Y, Chen XY, Li SM, Wei XY, Yao HM, Zhong DF. Pharmacokinetic studies of meloxicam following oral and transdermal administration in beagle dogs. Acta Pharmacol Sin. 2009;30(7):1060-4. doi: 10.1038/aps.2009.73, PMID 19543299.

27. Hasan SM, Shoaib MH, Hassan F, Rehman IU. Bioequivalence studies of two brands of meloxicam tablets in healthy Pakistani volunteers. Pak J Pharm Sci. 2009;22(2):199-204. PMID 19339233.

28. Winter CA, Risley EA, Nuss GW. Carrageenin-induced edema in hind paw of the rat as an assay for antiiflammatory drugs. Proc Soc Exp Biol Med. 1962;111:544-7. doi: 10.3181/00379727-111-27849, PMID 14001233.

29. Jain NK, Patil CS, Singh A, Kulkarni SK. A simple technique to evaluate inflammatory pain along with anti-inflammatory studies in carrageenaninduced paw edema. Indian J Pharmacol. 2001;33:114-5.

30. Pandey M, Belgamwar V, Gattani S, Surana S, Tekade A. Pluronic lecithin organogel as a topical drug delivery system. Drug Deliv. 2010;17(1):38-47. doi: 10.3109/10717540903508961, PMID 22747074.

31. Dreher F, Walde P, Luisi PL, Elsner P. Human skin irritation studies of a lecithin microemulsion gel and of lecithin liposomes. Skin Pharmacol. 1996;9(2):124-9. doi: 10.1159/000211408, PMID 8722607.

32. Naga Sravan Kumar Varma VN, Maheshwari PV, Navya M, Reddy SC, Shivakumar HG, Gowda DV. Calcipotriol delivery into the skin as emulgel for effective permeation. Saudi Pharm J. 2014;22(6):591-9. doi: 10.1016/j. jsps.2014.02.007, PMID 25561873.

33. Washington C, Washington N. Drug delivery to the skin. In: Wilson CG, Washington N, editors. Physiological pharmaceutics: biological barriers to drug absorption. 1st ed. Chichester: Ellis Horwood; 1989. p. 109-20.

34. Patrick E, Maibach HI. Predictive assays: animal and manand in vitro and in vivo. In: Rycroft RJG, Menné T, Frosch PJ, Benezra C, editors. Contact dermatitis. Heidelberg: Springer-Verlag; 1992. p. 706-47.

35. Schenkel L, Müller P, Pethica D. The therapeutic value of transdermal drug therapy. In: Gurny R, Teubner A, editors. dermal and transdermal drug delivery: new insights and perspectives. Stuttgart: WissenschaftlicheVerlagsgesellschaft; 1993. p. 173-85.

36. Ogiso T, Iwaki M, Paku T. Effect of various enhancers on transdermal penetration of indomethacin and urea, and relationship between penetration parameters and enhancement factors. J Pharm Sci. 1995;84(4):482-8. doi: 10.1002/jps.2600840418, PMID 7629741.

37. Keng PS, Basri M, Zakaria MRS, Rahman MBA, Ariff AB, Rahman RNZA, Salleh AB. Newly synthesized palm esters for cosmetics industry. Ind Crops Prod. 2009;29(1):37-44. doi: 10.1016/j.indcrop.2008.04.002.

38. Santoyo S, Arellano A, Ygartua P, Martín C. In vitro percutaneous absorption of piroxicam through synthetic membranes and abdominal rat skin. Pharm Acta Helv. 1996;71(2):141-6. doi: 10.1016/0031-6865(96)00004-0, PMID 8810580.

39. Sapra B, Jain S, Tiwary AK. Transdermal delivery of carvedilol containing glycyrrhizin and chitosan as permeation enhancers: biochemical, biophysical, microscopic and pharmacodynamic evaluation. Drug Deliv. 2008;15(7):44354. doi: 10.1080/10717540802327047, PMID 18712622.

40. Davis R, Primo-Davis SA. Assignee. Transdermal therapeutic formulation Davis R, Primo-Davis SA, inventors. United States patent US. Vol. 5(665); 1997 Sep 9. p. 378.

41. Loftsson T, Sigurdardóttir AM. Cyclodextrins as skin penetration enhancers. In:Proceedings of the eighth international symposium on cyclodextrins. Netherland: Springer; 1996. p. 403-6.

42. Akhtar N, Rehman MU, Khan HM, Rasool F, Saeed T, Murtaz G. Penetration enhancing effect of polysorbate 20 and 80 on the in vitro percutaneous absorption of ascorbic acid. Trop J Pharm Res. 2011;10(3):281-8.

43. Shin SC, Cho CW, Oh IJ. Effects of non-ionic surfactants as permeation enhancers towards piroxicam from the poloxamer gel through rat skins. Int 


\section{PICTORIAL ABSTRACT}

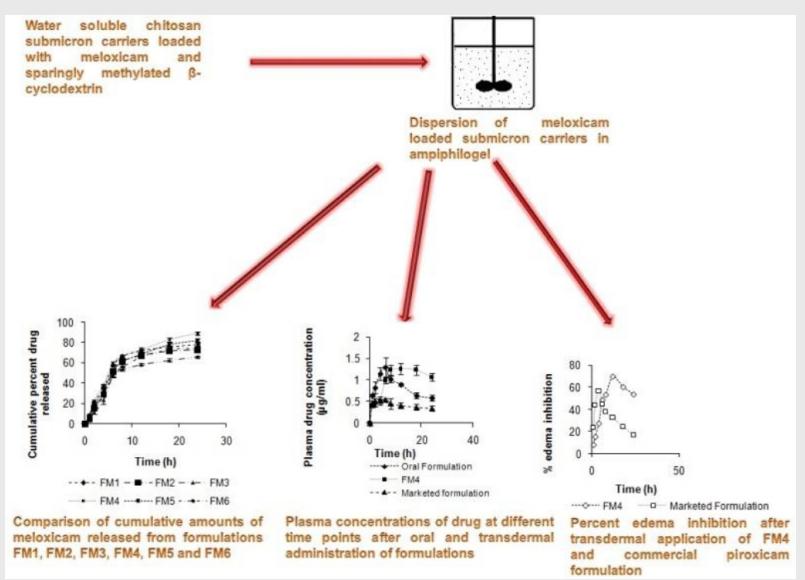

\section{SUMMARY}

The development of AMPGs can result in even distribution of drug throughout gel matrix and also enhance skin retention time of the carriers, resulting in increased permeation of the payload through the skin. AMPGs containing meloxicam loaded nanoparticles were prepared using Span 60/GMS as the gelling agent while Tween 80 as the gelling vehicle. Formulations were tested for rheological study, in vitro drug release and permeation, pharmacokinetic study, pharmacodynamic study, skin irritation study and stability. In-vitro release study was carried out using diffusion cell by dialysis membranes. GMS/Tween based formulations showed higher release rate of meloxicam as compared to Span 60/Tween 80 based formulations. Optimized formulation FM4 was found to cause inflammation reduction at larger extent and also more prolonged this effect as compared to marketed formulation. The AUCO-24h of meloxicam in plasma following transdermal administration of formulation FM4 was 2.52 times as compared to marketed piroxicam formulation. The anti-inflammatory effect of the prepared formulation was sustained for prolonged duration due to slow release of the drug.

Cite this article: Singhavi DJ, Yeole $\mathrm{P}$, Khan S. Preparation and in-vitro / in-vivo Characterization of Transdermal Amphiphilogel Loaded with Biodegradable Polymeric Submicron Carriers of Meloxicam for Treatment of Inflammation. Indian $\mathrm{J}$ of Pharmaceutical Education and Research. 2022;56(1):133-43. 